\title{
Romantismo das trevas
}

\section{Walnice Nogueira Galvão}

Resumo: A ruptura efetuada pelo romantismo requer apreciação de sua dupla face: a solar e a das trevas. Em atenção a essa ambivalência, um esboço das linhas mestras encaminha a seguir o exame do percurso de artistas que encarnam o ápice do romantismo solar (o francês Victor Hugo) e do romantismo das trevas (o norte-americano Edgar Allan Poe). Entre eles situa-se o inglês Byron, que partilha as duas tendências. Palavras-chave: romantismo solar, romantismo das trevas, Victor Hugo, Byron.

Abstract: The rupture made by Romanticism requires appreciation of its double side: Light and Dark Romanticism. In attention to this ambivalence, the perspective of a guideline allows us to analyze the journey of artists who embody the apex of Light Romanticism (the French author Victor Hugo) and Dark Romanticism (the American author Edgar Allan Poe). The English poet Lord Byron, who shares the two trends, lies between both writers. Keywords: Light Romanticism, Dark Romanticism, Lord Byron, Romantic rupture. 


\section{Uma nova estética}

O movimento da sensibilidade que começa nos fins do Setecentos, para dominar todo o Oitocentos, introduziu uma estética inédita. Ponto crucial da novidade é seu nexo com a Revolução Industrial, em reação ao industrialismo, à máquina e ao materialismo. Decorre daí uma série de consequências, que vai implicar a rejeição dos cânones do neoclassicismo, inclusive das Luzes e seu elogio da razão, trazendo à tona a valorização do irracional.

Instaurando a mescla de gêneros, o mais flagrante é aquilo que ocorre no teatro, onde o novo programa postula que não mais haverá tragédia e comédia separados, mas as duas juntas na mesma peça. Até aí, Racine e Corneille criavam tragédias de um lado, enquanto do outro Molière escrevia comédias. Verifica-se então a ascensão do drama, chamado de romântico ou burguês, misturando as duas vertentes. No processo, teve papel destacado Victor Hugo, que sistematizou o novo paradigma no prefácio de sua peça Cromwell e praticou a nova maneira na dramaturgia. A estreia de outra peça sua foi o marco histórico do episódio conhecido como "A batalha de Hernani", em que as claques de fãs vieram às vias de fato dentro do teatro.

Credita-se ao romantismo a invenção dos sentimentos e a perquirição dos estados d’alma: seu tema central é o amor. Por sua vez, a invenção dos sentimentos acarretou o apreço pela natureza enquanto projeção do coração humano. Rousseau, enaltecendo a promenade e a aura do viandante solitário, alça-se como precursor da ecologia. A noite seria um dos principais temas românticos; os poetas a cantaram como propícia à alma, acolhedora, nutriz do sonho e do devaneio. ${ }^{1}$ Nenhum poeta escapa de ter feito poemas sobre a noite; e Chopin, músico romântico, comporá os reputados Noturnos, para piano.

Nota-se o predomínio da poesia, gênero por excelência do romantismo. No bojo de uma contestação generalizada, perde vigência até o tamanho do verso comedido anterior, especialmente o decassílabo, típico do neoclassicismo. Segundo a nova estética, o verso deve corresponder ao impulso lírico, ao estado de ânimo: por isso se alonga, podendo atingir catorze ou dezesseis sílabas, ou mesmo ultrapassá-las. Quanto aos poetas, a tuberculose e a vida breve espreitam esses adoradores da morte. Mário de Andrade fala dos "cacoetes históricos que organizaram o destino do homem romântico", no ensaio que vai buscar seu título num poema de Casemiro 
de Abreu, "Amor e medo". ${ }^{2}$ Certos tópicos são reiterativos, como a metáfora do rapaz morto, tanto quanto a mulher anjo/criança/virgem/fada/visão e seu oposto, a Mulher Fatal, sumariando a timidez ante o feminino. Tais poetas, com raras exceções como Castro Alves e Victor Hugo, cantam o amor impossível, irrealizável.

Dados biográficos ajudam a esclarecer a questão. Álvares de Azevedo e Casimiro de Abreu morreram aos 21 anos, Castro Alves aos 24, Junqueira Freire aos 27, Fagundes Varela aos 36, destacando-se entre eles um verdadeiro ancião, Gonçalves Dias, que faleceu na provecta idade de 41 anos.

\section{Romantismo solar: Victor Hugo}

Quem melhor representa a face solar do romantismo é Victor Hugo, cuja vida, entre 1802 e 1885, praticamente se confunde com a história do Oitocentos.

Se indagássemos qual foi o escritor que mais influenciou outros, sem dúvida a resposta seria, mesmo sem o hélas de André Gide quando lhe perguntaram quem era o maior poeta francês: Victor Hugo. Tal presença pode ser constatada desde a Escandinávia até a Patagônia, e sobretudo na América Latina, por todo o século romântico e começo do seguinte. Até que as vanguardas, e a nova estética modernista, torcessem o pescoço da eloquência.

O século que assistiu à ascensão do proletariado, à presença das massas na vida pública, à tomada de partido dos escritores e artistas ante o novo fenômeno: esse é o século de Victor Hugo. Sua trajetória é exemplar. Traçando a contrapelo o projeto burguês de subir na vida, até hoje vigente, ele tratou de "descer na vida" ao repetidas vezes aliar-se às causas do povo, correndo o risco de perder, como de fato perdeu, seus privilégios. Este bem-nascido filho de general napoleônico agraciado com título de nobreza, aos dezoito anos, recebe pensão do rei Luís Xviır. Aos 23, é feito cavaleiro da Legião de Honra e assiste como convidado à sagração do rei Carlos x, em Reims. Aos trinta já é uma celebridade: católico, monarquista, poeta consagrado com vários livros publicados, dramaturgo de primeira plana (Cromwell, Hernani, Marion de Lorme) e romancista popular (Nossa Senhora de Paris). Só faltava a Academia, na qual seria recebido aos 41 anos. Seu discurso de posse, coisa inusitada, chama a atenção para as massas desvalidas, reivindicando para elas justiça e igualdade. E, coroando tudo, aos 43 anos o rei Luís Filipe assina decreto elevando-o a Par de França. 
Mas adveio a revolução de 1848, que se alastrou pela Europa, e Victor Hugo tomou o partido do povo insurreto, chacinado nas ruas à vista de todo mundo. Sobrevém-lhe a perda de seu título de nobreza. Pouco depois, ao ver os dois filhos encarcerados, acaba fugindo do país sob nome falso, para escapar à prisão. Logo seria oficialmente banido. Decorridos alguns anos, sai a anistia para os insurretos, mas o escritor a recusa, declarando que sua liberdade depende da liberdade de toda a França. Só regressaria em 1870, após vinte anos de exílio.

Volta a tempo para a Comuna de Paris, quando é eleito deputado, com uma avalanche de votos. Mais tarde, derrotada a Comuna, seria eleito senador, aproveitando o ensejo para discursar exigindo repetidas vezes anistia para os communards. Um admirador, Pedro II, visitou-o em Paris em suas viagens.

Morreu aos 83 anos, após doar seus manuscritos à Biblioteca Nacional. Tendo deixado instruções para ser enterrado como indigente, entretanto receberia exéquias oficiais de Estado, quando o povo de Paris saiu às ruas em peso para descobrir-se à passagem dos despojos de seu paladino; e repousaria no Panthéon.

Uma vida como essa, vivida durante o século do romantismo, marcou profundamente mais de uma geração de artistas. A trajetória de poeta heroico e libertário, condutor de povos, defensor dos oprimidos, que olha a história nos olhos e não se acovarda, banido por suas convicções, abdicando de posição social e honrarias, vai deflagrar a popularidade de Victor Hugo. Ele será o poeta romântico por excelência. Cabe a este visionário a glória, nada desprezível, de ter sido um dos primeiros a sonhar uma União Europeia, que chamou de Estados Unidos da Europa em discursos proferidos em duas datas revolucionárias: no Congresso Internacional da Paz (1849) e na Assembleia Nacional Francesa (1871). Sua quimera levaria mais de cem anos, incluindo duas guerras mundiais que devastaram o continente, para tornar-se realidade.

Escritor torrencial em poesia, ficção e teatro, levou avante a missão de concretizar o sonho de emancipar a humanidade de seus grilhões. A poesia que pratica é, portanto, uma arte de altos voos. Não por acaso escolheu para emblema a águia, que já o fora de Napoleão Bonaparte. Faz-se notar pela grandiloquência, pelas hipérboles, pelas apóstrofes e invectivas, pelas imagens titânicas. Expressa-se por antíteses, em jogos de luz e trevas, céus e abismos, gelo e fogo, libertação e opressão, espírito e matéria, ou demais imagens que contrapõem o sublime ao grotesco. No outro extremo, devota-se também a uma poesia intimista, erótica, doméstica e até familiar.

$\mathrm{Na}$ esteira do historiador Michelet, o primeiro a postular e mostrar o povo como agente da história - e não mais os reis, os líderes, os heróis -, Victor Hugo vai dar primazia em sua ficção à personagem coletiva popular, como se vê, por exemplo, 
em Os miseráveis. Essa tarefa caberá a Dickens nas letras inglesas e aqui a Euclides da Cunha.

Venerado e imitado no mundo todo, mas sobretudo na América Latina, veio da Argentina a expressão que rotularia todos os hugoanos, inclusive brasileiros: o "condoreirismo", pelo qual a águia europeia de Victor Hugo se aclimataria ao continente. A expressão designa essa poesia altissonante, voltada para vastos temas humanitários.

Entre nossos poetas, o modelo assinala-se sobretudo em Castro Alves. Os outros

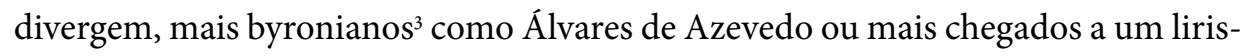
mo de raízes lusitanas, devendo muito a Almeida Garrett, como Gonçalves Dias e Casimiro de Abreu.

Para dar o resultado que deu em Castro Alves, tudo combinou. Uma grande causa humanitária é determinante, no caso a dos escravos, alicerçando a concepção do poeta como vate inspirado, arauto e profeta, anunciador do futuro e cantor da liberdade. Outra coincidência é a facilidade de versejar, pela qual Victor Hugo era reputado e que Castro Alves, muitas vezes provado em debates públicos, vai demonstrar. Ou uma dicção mais tonitruante, que tende à oratória, deixando na sombra uma excelente poesia intimista. E, não menos vital, o perfil do poeta engajado, cujos arroubos, ao expressar seu senso de missão, encarnam as tendências messiânicas do romantismo.

No brasileiro, à contraluz do confrade francês, ressalta a imaginação cósmica, panteísta e com pendor ao gigantesco, que torna o poeta uma testemunha da "marcha dos séculos", com heróis que "tropeçam na eternidade", visões dos "oceanos em tropa" e o "descerrar as cortinas do infinito". E o mesmo gosto da antítese e de seus contrastes, sondando os valores simbólicos da oposição entre luz (liberdade, emancipação, idealismo) e trevas (escravidão, opressão, ignorância).

Mais adiante, passado o romantismo e já em pleno naturalismo - influência tardia portanto -, o peso de Victor Hugo vai-se fazer sentir em Euclides da Cunha. Hugoano e castroalvino, às vezes dificulta a distinção, porque em certos pontos recebeu a marca de Victor Hugo já filtrado por Castro Alves. Pode-se aquilatar sua emoção, então, ao ser eleito para a Academia Brasileira de Letras como ocupante da cadeira cujo patrono é justamente Castro Alves, de quem fala no discurso de posse. Entre outros pontos de contato, também lhe dedicaria uma longa conferência, "Castro Alves e seu tempo". 
Prolongando Victor Hugo e Castro Alves, Euclides iria aderir à concepção, própria do romantismo, do escritor enquanto vate, presa das visões da inspiração, um condutor de povos que aponta o rumo do futuro. Vincula-se a ambos na dedicação às causas humanitárias, no socialismo difuso e na defesa dos oprimidos. São similares a grandiloquência, a retórica, o andamento desmesurado, bem como o uso excessivo da antítese, que em seu caso chega até à predileção pelo oximoro. Seus heróis seriam os sertanejos.

\section{Na escuridão}

Entretanto, o romantismo tem outra face. Se uma é jovem, rósea, imersa nos sentimentos e na natureza, solar em suma, a outra é noturna, noir ou dark. ${ }^{4}$ Esta outra face manifesta-se forçosamente nos mais recalcitrantes à revolução industrial, que encaram com apreensão o predomínio da indústria e da máquina sobre as pessoas, ou do capital sobre o trabalho, acarretando a uniformização da vida, a automatização, a linha de montagem. A tudo isso vinha acrescentar-se a degradação que assolava homens, tecido urbano e paisagem.

Rebeldes, não conformistas, intransigentes, estes poetas, levando avante suas propostas, avançariam por vias proibidas como o satanismo, o esoterismo, o sobrenatural, o sadismo. Uma de suas mais notáveis derivações é a figura do poeta maldito. Dentro dessa linha, que mostra desdém pelas convenções morais e sociais, que louva o Diabo, que tem atração pela morte como meta final, que brinca com as ideias de putrefação e de decomposição, ainda outras figurações se seguiriam. É o romantismo das trevas que cria a Mulher Fatal, vendo no feminino um ser maléfico que seduz os homens para fadá-los à destruição. Não por acaso é Salomé - aquela que recebeu numa bandeja a cabeça de João Batista, degolado a seu pedido - o ícone feminino da época, tanto na literatura como na música e nas artes plásticas. A fantasmagoria da mulher castradora predomina e se estende a outras comparsas de Salomé. Ou seja, é sempre o tema romântico do amor, todavia tratado pela negativa, pelo avesso. Mais tarde, na fase final, Barbey d'Aurevilly escreveria As diabólicas, que já se tornou filme duas vezes, dando bem uma ideia de como o romantismo das trevas encara a mulher.

PRAZ, Mario. La carne, la morte e il diavolo nella letteratura romantica. Roma: Sansoni, 1996; LEVIN, Harry. The power of darkness. New York: Penguin, 1958; BACHELARD, Gaston. A água e os sonhos. São Paulo: Martins Fontes, 1998, esp. cap. II. 
Daí a um passo está o interesse pela psicologia anormal, pelo crime e pela mentalidade do criminoso. Em outro patamar, criou-se a categoria artística do belo-horrível, que seria posteriormente aplicada ao barroco, tendo como corolário o decadentismo e a estética das ruínas.

Entretanto, a exacerbação da tendência é inaugural, e logo no início do romantismo postam-se o Marquês de Sade e o sadismo, com o louvor do mal, da dor e do sofrimento alheios, infligidos ao outro com prazer. É bom lembrar que Sade estava preso na Bastilha quando esta foi tomada em 14 de julho de 1789.

O culto ao Diabo alastra-se, os poetas conjurando uma projeção de si próprios na figura do Lúcifer bíblico, o anjo que se insurgiu contra Deus, o maior adversário da ordem constituída: lição aprendida no Paradise lost de Milton e seu grande protagonista, um século antes. Entre os pioneiros ressalta a arte única de William Blake que, dilacerado entre a libertação trazida pela Revolução Francesa e a escravização do homem pela engrenagem industrial nascente, conversava com anjos, em meio a visões celestiais e demoníacas. Torna-se comum, quase uma moda, que os poetas, inclusive os solares, consagrem sua lira a Satanás. Victor Hugo compôs dois longos poemas míticos: "Dieu" e "La fin de Satan". E Mefistófeles é o antagonista supremo do Fausto, de Goethe, apesar de seu autor ser outro romântico solar.

Herói predileto dessa época é Caim, o maldito, o primeiro assassino da história, o fratricida, o pária, o perseguido. Poeta romântico imbuído de seu papel faria poemas sobre e para Caim, do que não escapariam nem mesmo Victor Hugo e Byron. São, portanto, dois os protagonistas dominantes do romantismo das trevas: o Diabo e Caim. O terceiro, que seria o poeta maldito, é antes uma persona que um protagonista, ou seja, uma máscara que o artista envergava. Dentro de um quadro como esse, não é de estranhar o surgimento da convenção do incesto. Byron proclamava uma relação incestuosa com sua meia-irmã Augusta, e Álvares de Azevedo procuraria emulá-lo.

\section{O percurso exemplar de Byron}

Este grande poeta viveu 36 anos apenas, a cavaleiro da virada de século entre o Setecentos e o Oitocentos. Fez estudos em Cambridge, adquirindo uma educação clássica, em que se impregnou de grego e latim. Mais tarde ganharia a reputação de dom-juan, de grande amante: era ateu, adversário da moral tradicional e um tremendo crítico do progresso. 
Tinha ideias políticas avançadas. Quando tomou posse de seu assento na Câmara dos Lordes, discursou defendendo os operários que tinham destruído seus teares e sobre os quais pendia a ameaça da pena de morte. Mas não pôde prosseguir em sua carreira parlamentar na Inglaterra, passando a envolver-se em ativismo libertário no exterior. Primeiro na Itália, em aliança com os Carbonários que se encarniçavam em derrubar o jugo estrangeiro. Ainda não uma nação, a Itália, então sob soberania em parte austríaca e em parte espanhola, só mais tarde sacudiria o jugo e se unificaria no Risorgimento. Depois, na Grécia ocupada pelos turcos, seria nomeado membro do Comitê Nacionalista da Resistência, posto que ocupou até a morte.

Viveria muitos anos no exílio, no início na Suíça, mas mais tempo na Itália, especialmente em Veneza. Sua viagem precoce ao Orientes chamou a atenção para aquela área do mundo, e em particular para as tradições gregas, turcas e árabes, que integrariam a sua poesia. Faz parte dessa mística sua famosa travessia do Helesponto a nado, em 3 de maio de 1810. Byron tinha uma visão universalista da militância política. E se a história não tivesse pregado uma peça, é plausível pensar que ele e Che Guevara se entenderiam muito bem.

Publicara os dois primeiros cantos de Childe Harold's pilgrimage em 1812, aos 24 anos. Autobiografia romanceada em versos, traz relatos de suas viagens e comentários a acontecimentos contemporâneos, como, por exemplo, o baile havido em Bruxelas às vésperas da batalha de Waterloo, onde mostra o quanto é afiada sua verve de crítica social. Embora mais tarde acrescentasse outros cantos, o poema afinal ficaria incompleto. Foi um sucesso imediato, e sucesso popular: de março a dezembro, tiraram-se cinco edições e se multiplicaram as traduções. $\mathrm{Na}$ época, a alta literatura andava estranhada dos leitores, sendo considerada enfadonha, tediosa: com Byron, o romantismo caiu imediatamente no gosto do público.

Esse é um daqueles autores que fazem de sua existência uma obra de arte, e que transportam suas interessantíssimas vivências para dentro daquilo que escrevem. Para os artistas de seu tempo, também fez parte dessa mesma vivência ser blasfemo, iconoclasta, crítico social; e, avançando mais ainda, praticar um certo satanismo, manifestar interesse pelo oculto, pelo esoterismo, pela necrofilia, e assim por diante. Com Byron, a exemplo de vários outros, inicia-se o culto da supracitada categoria estética típica do romantismo, o belo-horrível. Já alguém menos 
afoito como Casimiro de Abreu prefere o que chamou de "belo doce e meigo", que cabe mais à face solar.

Afora Childe Harold's e o extraordinário Don Juan, poema herói-cômico do mais alto nível, Byron compôs $O$ Giaour (em turco, o infiel ou não muçulmano), $O$ corsário, Caim, O sítio de Corinto, Manfredo, Beppo, A noiva de Abydos, Sardanápalo, vários dos quais são dramas em verso. A notar que em sua obra se destacam trechos do mais refinado lirismo.

\section{Reverberações}

Para ver-se onde as coisas começam e aonde vão imprevisivelmente parar, basta lembrar que o famoso romance Frankenstein (1818) foi escrito, se não por inspiração de Byron, pelo menos como um desafio interno a seu cenáculo. A crônica é a seguinte: Byron e outro grande poeta inglês íntimo das trevas, Shelley, alugaram casas à beira de um lago, na Suíça, e lá residiram por um bom tempo, com seus séquitos, em intenso convívio. À maneira romântica, faziam passeios - as renomadas promenades que Rousseau preconizava, para devanear em meio à natureza -, convescotes, ceias à luz de velas, elegantes jogos de salão, brincadeiras artísticas e literárias. Uma delas consistiu na aposta de escrever algo sobrenatural, sobre vampiros ou lobisomens. Byron fez uma tentativa, a que não deu continuidade; o dr. Polidori, seu médico, escreveu O vampiro; e a esposa de Shelley, Mary Shelley, escreveu Frankenstein (1818), um dos mais famosos e populares romances do gênero, traduzido em inúmeras línguas, reeditado até hoje sem cessar, e que faria uma carreira insigne no cinema e na televisão.

Tivemos nossos byronianos, e o principal deles, aqui mesmo em São Paulo, foi Álvares de Azevedo, o qual, à boa moda do tempo, morreu aos 21 anos ("Se eu morresse amanhã viria ao menos/ Fechar meus olhos minha triste irmã...”). Excelente poeta, também tentou criar para si a reputação de incestuoso. É ele um dos principais objetos do supracitado "Amor e medo" de Mário de Andrade, no qual o ensaísta sustenta que a morte precoce de tantos deles mostra receio da sexualidade madura. Para Mário, apesar das orgias e bacanais que descreveu, provavelmente Álvares de Azevedo era inexperiente, senão mesmo virgem. Em sua lira, a mulher aparece cindida em duas, que são, em resumo, a Santa e a Prostituta. Um grande poeta, tão admirado por Mário de Andrade quanto por Antonio Candido. 


\section{Extramuros}

É impossível falar do romantismo das trevas sem incluir o fôlego novo que, bem depois de ter caducado, adquiriu no cinema e na televisão. Pois tudo isso que povoa o audiovisual - vampiros, Frankensteins, monstros - é invenção da literatura romântica, numa linhagem que se chamou "o Gótico". Dados recentes mas certamente incompletos recenseiam 156 filmes de Drácula, 120 curtas-metragens, vinte telenovelas, dezenove séries de TV e seiscentas histórias em quadrinhos.

A fonte reside no terror atávico que os vivos têm dos mortos, manifestando-se na criação de fantasmas, avantesmas, assombrações, almas penadas: os mortos-vivos se tornariam um grande filão cinematográfico. Essa é a origem da maior parte dos rituais e cultos, que têm por objetivo impedir que os mortos voltem: em francês, alma do outro mundo é revenant, ou "o que volta". Em português, dizemos "alma penada”, ou seja, aquela que por castigo cumpre pena de vagar pelo mundo dos vivos em vez de ficar bem quietinha no mundo dos mortos. Neste campo, impõe-se uma distinção tripla, a permitir que as inúmeras variedades possam ser agrupadas em três arquétipos principais.

O primeiro é o de Drácula, aquele que não morre, alimentando-se de sangue e infectando os outros: cabem aqui os vampiros em geral.

O segundo é o de Frankenstein, agenciado por mão humana, morto-vivo construído com pedaços de corpos desmembrados. Seria assim um precursor dos transplantes de órgãos, que hoje em dia geram histórias de terror na vida real; ou, mais recentemente, da plastificação de cadáveres para exposições de arte.

O terceiro é o de $O$ médico e o monstro, ou da dupla personalidade. Trata-se de uma variante da multimilenar "sibling rivalry" de tantos mitos, entre eles Caim e Abel, focalizando gêmeos ou irmãos inimigos, um bom e outro mau.

Todos os três estão às voltas com a ciência, e seus protagonistas (ou antagonistas) são invariavelmente cientistas, com título de doutor. Em Drácula é o dr. Van Helsing; em Frankenstein, é o dr. Frankenstein que dá seu próprio nome ao monstro que gerou; e no terceiro o dr. Jekyll é médico e vítima da ciência.

Nesses rebentos da imaginação podemos ver avatares do "complexo de Prometeu", ou a punição que pende sobre os homens pelo roubo do fogo aos deuses. Esta é uma das respostas possíveis à revolução industrial com sua valorização da ciência e da tecnologia, estratégicas para capturar e transformar a energia da natureza. Paira o risco de que fuja ao controle, dando margem a engenhos nunca vistos, assombrando e aterrorizando os seres humanos - a que aludem nas parábolas o aprendiz de feiti- 
ceiro ou o gênio da lâmpada de Aladim. O processo assim desencadeado levaria a uma invenção que veio apequenar qualquer delírio catastrófico romântico, a fissão do átomo, ainda nos arcanos do futuro.

\section{Edgar Allan Poe}

$\mathbf{O}$ romantismo das trevas conhece seu mais alto ponto na poesia de Baudelaire, o poeta maldito, da deformação, da perversão. Baudelaire é um dos maiores poetas do mundo, tão importante na segunda geração romântica quanto Victor Hugo e Byron na primeira; e, para muitos críticos, ainda mais importante.

No lado das trevas incluem-se Edgar Allan Poe, os romancistas góticos ingleses, que desenvolveram o gênero mais do que todos, e o alemão Hoffman dos contos que os antecedeu. Sobressai neles a preocupação dos românticos com a morte. Nota-se a deleitação, o embelezamento, a idealização da morte e da putrefação: a imaginação vê no corpo vivo e belo o futuro cadáver. Não é à toa que Baudelaire se transforma no profeta de Poe, a quem traduz e divulga na França.

Após escasso reconhecimento em seu tempo e seu país, a reviravolta na recepção da obra de Poe deu-se mediante essa descoberta quase póstuma. Poeta maldito avant la lettre, além de criar aqueles horrores, também se recomendava pela dipsomania, enquanto elogiava o ópio em seus textos.

Os românticos, como ninguém ignora, lançaram a moda dos tóxicos, por acreditarem que desencadeavam a inspiração e facultavam o transe. Poeta que se prezasse tomava ópio, como Coleridge, e descrevia suas viagens para os leitores. Popularidade não faltou às Confissões de um comedor de ópio de Thomas de Quincey, divulgadas por Baudelaire, que as traduziu e adaptou, acrescentando um estudo de próprio punho e dando ao conjunto o título de Les paradis artificiels. O próprio Baudelaire era usuário, e bem mais tarde Cocteau igualmente. Para Rimbaud e Verlaine, assim como para Poe, as bebidas espirituosas é que preenchiam essa função. Os artistas passariam a tomar absinto, o qual, acusado de causar cegueira e loucura, encontra-se até hoje banido da França. Nos anos 1930, Walter Benjamin não resistiu a provar o haxixe e a escrever sobre a experiência, em "Haxixe em Marselha". E a Beat Generation de Kerouac, Ginsberg e Ferlinghetti fez do uso de várias drogas um programa e uma estética: vide $O$ almoço $n u$, de William Burroughs. Não fica alheio Aldous Huxley, autor de As portas da percepção, em que tematiza a ingestão de ácido lisérgico. 
Foi assim que um visionário anotador de alucinações - indisfarçáveis visitações pessoais -, acicatado pelo demônio da intemperança e sujeito a crises de delirium tremens, acabou por se tornar epítome do poeta maldito. Veio pronto em obra e vida, a qual, atribulada, provou-se autodestrutiva como poucas. Seria curta, não ultrapassando os 41 anos, que coincidiram com a primeira metade do Oitocentos.

Após um século de psicanálise, não mais passam por tão inocentes os devaneios sulfúricos de Poe, a quem Marie Bonaparte, discípula dileta de Freud, dedicou um livro (Edgar Allan Poe, uma biografia). Aliando dados da biografia a dados da obra, Nabokov insinuou em Lolita a pecha da perversão, alçando Poe a precursor em pedofilia, para não falar em incesto. A começar por Virginia Clemms, esposa e prima, contando 14 anos (só dois a mais que Lolita) quando se uniu ao marido de 27 , que cedo a veria morrer de tuberculose. Em Annabel Lee, que dá a rima para "In a kingdom by the sea" - território imaginário onde se situa o poema -, os amantes são crianças ("I was a child and she was a child"). As pistas levantadas por Nabokov dão-lhe parentesco com Lewis Carroll e sua atração por menininhas. Mas outras pistas sugerem impotência e bloqueios sexuais, entre demais amenidades.

O paladino da descoberta europeia foi Baudelaire, passando para o francês as Histórias extraordinárias, propondo uma versão em prosa de "O corvo", tomando-o como objeto de estudos críticos. O poema teve o privilégio de ser traduzido por Machado de Assis e por Mallarmé, em meio a Les poëmes d'Edgar Poe, para os quais, à guisa de prefácio, compôs um soneto apologético, Le tombeau d'Edgar Poe. Valéry preferiu a prosa de especulação cosmológica de Eureka e incorporou elementos da estética.

Esses poetas identificaram-se com o Poe doutrinador da poesia pura e da arte pela arte - ideais do parnasianismo e do simbolismo -, bem como com o defensor da concepção do poeta enquanto criador voluntário no comando de sua inspiração. Neste caso, seu texto mais influente seria "A filosofia da composição", em que relata minuciosamente como escreveu "O corvo". É bem verdade que há estudiosos e artistas de língua inglesa mais reticentes quanto à qualidade de sua poesia, mas que ainda assim o louvam pela musicalidade do verso e pela força das imagens, mergulhadas em atmosfera etérea e evanescente. De todo modo, a voga francesa foi tal que alguns deles houveram por bem acautelar os leitores de que Edgar Allan Poe e Edgarpo não são a mesma pessoa. Mas críticos de primeira linha deram-lhe a atenção que merece, entre eles Mario Praz, Spitzer, Walter Benjamin, Bachelard, Harry Levin, Toni Morrison. ${ }^{6}$ of "The fall of the house of Usher". In: Twentieth century interpretations of "The fall of the house of Usher". 


\section{Os contos de Poe}

O Poe inigualável é aquele da prosa dos contos, que exploram toda a gama dos horrores de uma imaginação desenfreada.

Há canibalismo. Há que optar entre cair num poço sem fundo e ser retalhado por um pêndulo afiado que se acerca. Há a morte pela peste, assim como a incineração em vida. Há cataclismos e catástrofes pairando no horizonte. Há o encontro de um navio fantasma, juncado de cadáveres em putrefação. Ou o azar de esbarrar num manicômio adepto de uma terapia copiada do linchamento sulista norte-americano, que cobre as vítimas de alcatrão e plumas. Há o pesadelo de ser enterrado ou emparedado vivo. Nesse universo macabro, um dos segredos sadomasoquistas de Poe é dar forma aos mais recônditos pavores arcaicos, de crianças e adultos.

Entretanto, também há os prazeres - e que prazeres - que o mestre da "viagem maravilhosa" oferece. Que criança não gostaria de ser pirata? E qual delas não sonhou decifrar um mapa desenhado com tinta invisível, chave para um tesouro enterrado, protegido por esqueletos e caveiras? Entre tantos sustos vicários, conta-se ainda o de ser arrebatado por sorvedouros e vórtices. Ou aportar na Lua de balão. Ou então enfrentar a alvura fantasmal da Antártida. Ou despencar no maelstrom e retornar são e salvo, embora o cabelo tenha encanecido no trajeto.

Dentre as fantasmagorias oitocentistas, nada escapa à prosa oracular de Poe, cheia de presságios e premonições: a hipnose, a telepatia, o magnetismo, a catalepsia, o sonambulismo, os espectros, as almas penadas, os avantesmas, a transmigração dos espíritos, as assombrações mais diversificadas. Em suma, as incursões pelo sobrenatural ou pelos estados crepusculares entre a vigília e o sono. Potenciados pela ansiedade e a angústia, sucedem-se taras, incestos, maldições hereditárias, reminiscências atávicas, desdobramento do eu, mutilações, tortura, crime: crime perfeito porque gratuito, no entanto confessado devido a uma sinistra (masoquista?) compulsão pelo castigo.

Como se não bastasse, há mais um Poe, inventor da ficção policial e criador de Dupin, o primeiro detetive literário. São três os contos precursores: "Os crimes da

New Jersey: Prentice Hall/ Englewood Clifford, s.d.; BENJAMIN, Walter. Sobre alguns temas em Baudelaire. In: Walter Benjamin, Max Horkheimer, Theodor W. Adorno, Jürgen Habermas. São Paulo: Abril Cultural, Os Pensadores, 1975. Ver também as alusões a Poe nas duzentas páginas do dossiê "Baudelaire", in: BENJAMIN, Walter. Passagens. Belo Horizonte/São Paulo: UFMG/Imprensa Oficial, 2006; MORRISON,Toni. Playing in the dark - Whiteness and the literary imagination. New York: Random House, 1993.

Teresa revista de Literatura Brasileira [12|13]; São Paulo, p. 65-78, 2013 • 77 
rua Morgue", com sua sequência “O mistério de Marie Rogêt", e "A carta roubada”. A ênfase que Dupin reservava à pura dedução intelectual torna-o ancestral imediato de Sherlock Holmes. Lacan teve a honra de relançar Poe, ao dedicar nos Écrits todo um estudo a "A carta roubada", com base na versão baudelairiana, no qual analisa a eficácia simbólica do objeto da narrativa.

Em suma, neste rápido esboço fica claro que o romantismo, solar ou das trevas, persiste como uma fonte inesgotável de alta literatura, que se recomenda pelo prazer de ler.

Walnice Nogueira Galvão é professora titular de Teoria Literária e Literatura Comparada na UsP, visiting scholar da Columbia University e professora visitante da Université de Paris viı e da University of Texas System. É autora de Euclidiana: ensaios sobre Euclides da Cunha (Companhia das Letras, 2009); Mínima mímica (Companhia das Letras, 2008); Tapete afegão (Companhia das Letras/ Nacional, 2008); A donzela guerreira. Um estudo de gênero (Senac, 1998), entre outros. 